\title{
TEORES DE ALUMÍNIO TROCÁVEL E NÃO TROCÁVEL APÓS CALAGEM E GESSAGEM EM LATOSSOLO SOB SISTEMA PLANTIO DIRETO $\left({ }^{\mathbf{1}}\right)$
}

\author{
FERNANDO CÉSAR BACHIEGA ZAMBROSI $\left({ }^{2 *}\right)$; LUÍS REYNALDO FERRACCIÚ ALLEONI $\left({ }^{3}\right)$; \\ EDUARDO FÁVERO CAIRES $\left({ }^{4}\right)$
}

\begin{abstract}
RESUMO
O sistema plantio direto (SPD) contribui para o incremento dos teores de matéria orgânica (MO) no solo, o que pode alterar as relações entre os teores de alumínio (Al) trocável e não trocável, devido à complexação desse cátion. Este estudo foi realizado com o objetivo de avaliar o efeito da calagem e da gessagem nos teores de $\mathrm{Al}$ trocável $(\mathrm{Al}-\mathrm{KCl})$, $\mathrm{Al}$ trocável + não trocável $\left(\mathrm{Al}-\mathrm{CuCl}_{2}\right)$ e $\mathrm{Al}$ não trocável em amostras de Latossolo Vermelho cultivado há 55 meses no SPD, no município de Ponta Grossa (PR). Na implantação do sistema sobre uma pastagem nativa, entre os meses de julho e outubro de 1998, foram aplicadas 4,5 $\mathrm{tha}^{-1}$ de calcário em superfície, em única aplicação, ou parceladas em três aplicações anuais de 1,5 $\mathrm{t} \mathrm{ha}^{-1}$, ou ainda em uma aplicação, sendo o corretivo incorporado a $20 \mathrm{~cm}$ de profundidade. Nas subparcelas, foram aplicadas três doses de gesso: 3, 6 e $9 \mathrm{t} \mathrm{ha}^{-1}$. A calagem reduziu os teores de $\mathrm{Al}-\mathrm{KCl}$, $\mathrm{Al}-\mathrm{CuCl}_{2}$ e de $\mathrm{Al}$ não trocável, que se relacionaram negativamente com o pH do solo. Mesmo em condições de elevada acidez, os teores de Al trocável foram baixos, predominando no solo o $\mathrm{Al}$ não trocável, que representou $98 \%, 95 \%, 91 \%$ e $89 \%$ do Al extraído nas profundidades de 0-5, 5-10, 10-20 e 20-40 cm respectivamente. Não foi detectado efeito do gesso nos teores de nenhuma das formas de Al.
\end{abstract}

Palavras-chave: acidez do solo; calagem superficial; calcário incorporado; gesso; $\mathrm{Al}-\mathrm{KCl} ; \mathrm{Al}_{-} \mathrm{CuCl}_{2}$.

\section{ABSTRACT \\ EXCHANGEABLE AND NON-EXCHANGEABLE CONTENTS OF ALUMINUM AFTER LIME ANG GYPSUM APPLICATION IN AN OXISOL UNDER NO-TILL SYSTEM}

No-tillage (NT) system contributes for the increase of soil organic matter (OM) contents, changing the ratio between exchangeable and non-exchangeable Al due to cation complexation. This study was carried out to evaluate the effect of lime and gypsum application in the contents of exchangeable aluminum $(\mathrm{Al}-\mathrm{KCl})$, exchangeable + non-exchangeable aluminum $\left(\mathrm{Al}-\mathrm{CuCl}_{2}\right)$, and non-exchangeable $\mathrm{Al}$ from samples of a dystrophic clayey Rhodic Hapludox under NT for 55 months, in Ponta Grossa - PR. The NT system was implemented on a native pasture between July and October of 1998. Three methods of lime application were evaluated: a single application of $4.5 \mathrm{t} \mathrm{ha}^{-1}$, either incorporated down to $20 \mathrm{~cm}$ or surface applied, and $1.5 \mathrm{t} \mathrm{ha}^{-1}$ applied in each of three years. In the subplots, 3, 6 or $9 \mathrm{t} \mathrm{ha}^{-1}$ of gypsum were applied. The liming decreased contents of $\mathrm{Al}-\mathrm{KCl}, \mathrm{Al}-\mathrm{CuCl}_{2}$ and non-exchangeable $\mathrm{Al}$. Both $\mathrm{Al}$ forms related negatively with soil $\mathrm{pH}$. Even with large soil acidity, exchangeable $\mathrm{Al}$ contents were low, and non-exchangeable $\mathrm{Al}$ was the predominant form, representing 98, 95, 91, and $89 \%$ of total $\mathrm{Al}$, at $0-0.05 ; 0.05-0.1 ; 0.1-0.2$, and 0.2-0.4 m, respectively. Gypsum application did not affected $\mathrm{Al}-\mathrm{KCl}, \mathrm{Al}-\mathrm{CuCl}_{2}$ and non-exchangeable contents.

Key words: soil acidity; surface liming; lime incorporation; gypsum; $\mathrm{Al}-\mathrm{KCl} ; \mathrm{Al}-\mathrm{CuCl}_{2}$.

$\left({ }^{1}\right)$ Parte da Dissertação de Mestrado do primeiro autor apresentada à Escola Superior de Agricultura "Luiz de Queiroz", da Universidade de São Paulo. Recebido para publicação em 7 de fevereiro de 2006 e aceito em 24 de novembro de 2006. E-mail: zambrosi@iac.sp.gov.br $\left(^{*}\right)$ Autor correspondente.

$\left({ }^{2}\right)$ Centro de Pesquisa e Desenvolvimento de Solos e Recursos Ambientais, IAC, Caixa Postal 28, 13012-970 Campinas (SP).

$\left({ }^{3}\right)$ Departamento de Ciência do Solo, ESALQ/USP, Caixa Postal 9, 13418-900 Piracicaba (SP).

(') Departamento de Ciência do Solo e Engenharia Agrícola, UEPG, Av. Carlos Cavalcanti, 4748, 84030-900 Ponta Grossa (PR). 


\section{INTRODUÇÃO}

A interação entre o alumínio (Al) e a matéria orgânica (MO) é uma das reações que mais influencia as propriedades dos solos ácidos (URRUTIA et al., 1995). A fração orgânica do solo possui a capacidade de complexar cátions, dentre eles o $\mathrm{Al}$ (VANCE et al., 1996). Desse modo, no sistema plantio direto (SPD), devido aos maiores teores de MO do que no sistema convencional de cultivo com preparo do solo (Lovato et al., 2004), a quantidade de $\mathrm{Al}$ complexado (Al-MO) torna-se de acentuada importância, como constatado por CAMBRI (2004) para amostras de solos cultivados sob SPD de diferentes localidades brasileiras, em que o Al-MO predominou sobre a forma trocável $\left(\mathrm{Al}^{+3}\right)$.

Na fase sólida do solo, a distribuição entre formas de $\mathrm{Al}$ trocável e $\mathrm{Al}$ não trocável, a qual inclui o Al-MO, é obtida com o emprego de diferentes extratores (PionKe e CoRey, 1967). O teor de Al trocável é extraído com solução de $\mathrm{KCl} 1 \mathrm{~mol} \mathrm{~L}^{-1}$, que corresponde à fração adsorvida por forças eletrostáticas, formando complexos de esfera externa (JARdine e ZelaZnY, 1996). Para a extração do Al-MO pode ser empregada a solução de $\mathrm{CuCl}_{2} 0,5 \mathrm{~mol} \mathrm{~L}^{-1}$, com maior poder de extração do que o $\mathrm{KCl}$ (MENDONÇA e Rowell, 1994), ou outros extratores como o pirofosfato de sódio (Álvarez et al., 2002). Contudo, a extração com esse último superestima o $\mathrm{Al}$ ligado à MO (García-Rodeja et al., 2004), e o $\mathrm{CuCl}_{2}$ tem sido proposto como o melhor extrator para estimativa do Al orgânico (KAISER e ZECH, 1996).

$\mathrm{O} \mathrm{CuCl}_{2}$ extrai o $\mathrm{Al}$ ligado à $\mathrm{MO}$ em complexos de baixa à média estabilidade (URRUTIA et al., 1995), sendo denominado de "Al não trocável potencialmente reativo" (Juo e KAMPRATH, 1979). Toda forma de Al capaz de doar prótons em um meio com $\mathrm{pH}$ menor do que 7,0 é denominada de $\mathrm{Al}$ reativo, e a extração com $\mathrm{CuCl}_{2}$ dá uma rápida e simples estimativa do reservatório de $\mathrm{Al}$ potencialmente reativo em solos fortemente ácidos (SHIGEMITSU, 1975). A diferença entre os teores de $\mathrm{Al}$ extraídos em $\mathrm{KCl}$ e em $\mathrm{CuCl}_{2}$ é utilizada para estimar o Al-MO (JUO e KAMPRATH, 1979; URRUTIA et al., 1995). Entretanto, a extração com $\mathrm{CuCl}_{2}$ não extrai apenas a forma de $\mathrm{Al}$ ligado à fração orgânica do solo (Hargrove e ThOMAS, 1981; OAtes e KAMPRATH, 1983). Deste modo, tem se optado por adotar o termo Al não trocável para o teor do elemento obtido pela diferença entre os teores de $\mathrm{Al}$ extraídos em $\mathrm{CuCl}_{2}$ e em KCl (Figueiredo e Almeida, 1991). A participação relativa da forma $\mathrm{Al}-\mathrm{MO}$ na extração com $\mathrm{CuCl}_{2}$ depende da mineralogia do solo e da profundidade em que a amostra de terra foi coletada (JUO e KAMPRATH, 1979). Segundo esses autores, a diferença entre o Al$\mathrm{CuCl}_{2}$ e o Al-KCl nas camadas superficiais do solo (horizonte A) é dada pelos complexos orgânicos de
$\mathrm{Al}$, enquanto para o subsolo (horizonte $\mathrm{B}$ ), tal diferença é atribuída ao polímero de $\mathrm{Al}-\mathrm{OH}$ bem como às formas metaestáveis de hidóxidos de $\mathrm{Al}$.

O efeito negativo da acidez do solo e da toxidez por $\mathrm{Al}$ na produção agrícola não tem sido observado na maior parte dos solos cultivados no SPD, e a ausência de resposta das culturas à calagem, nesse caso, tem sido comum (CAIREs et al., 1998, 1999, 2005, 2006; AlLEONi et al., 2003, 2005). A menor toxicidade do $\mathrm{Al}$ encontrada no SPD está associada com a complexação do elemento pela $\mathrm{MO}$, que promove a remoção do Al da solução do solo (Hargrove e THOMAs, 1981), e a formação de complexos com o carbono orgânico dissolvido (ZAMBRosi et al., 2007), pois a biodisponibilidade e o potencial tóxico dos elementos no ambiente dependem de sua especiação na solução do solo (CANCĖS et al., 2003).

Como conseqüência, as doses de corretivo da acidez têm diminuído no SPD, chegando a ocorrer até mesmo suspensão de sua aplicação em algumas áreas cultivadas. No entanto, a acidificação, o revolvimento do solo e a decomposição de MO podem favorecer a alteração da forma não trocável do $\mathrm{Al}$ para formas mais disponíveis às plantas. Essa possibilidade justifica os estudos para melhor conhecimento da relação entre o $\mathrm{Al}$ trocável e o não-trocável, bem como a variação perante as práticas de manejo do solo, como a calagem e a gessagem.

Este trabalho foi desenvolvido com o objetivo de avaliar os teores de $\mathrm{Al}$ extraído com $\mathrm{KCl}(\mathrm{Al}-\mathrm{KCl})$, extraído com $\mathrm{CuCl}_{2}\left(\mathrm{Al}-\mathrm{CuCl}_{2}\right)$, e o $\mathrm{Al}$ não trocável em função de formas de aplicação de calcário e doses de gesso em Latossolo cultivado sob SPD.

\section{MATERIAL E MÉTODOS}

Foram utilizadas amostras de um experimento de campo instalado em 1998 em uma pastagem nativa no município de Ponta Grossa (PR), localizado a $25^{\circ} 06^{\prime} \mathrm{S}$ e $59^{\circ} 09^{\prime} \mathrm{W}$. Os resultados da análise química, obtidos segundo métodos citados em PAVAN et al. (1992) e granulométricas, segundo métodos da EMBRAPa (1997), do Latossolo Vermelho distrófico textura argilosa, antes da instalação do experimento, estão na tabela 1.

O delineamento experimental empregado foi o de blocos ao acaso com parcelas subdivididas e três repetições. Nas parcelas, foram testados quatro tratamentos de calcário dolomítico com $89 \%$ de PRNT, definidos de acordo com a necessidade de calagem para elevação da saturação por bases do solo a $70 \%$, na camada de $0-20 \mathrm{~cm}$ : (a) testemunha - sem calcário (T1); (b) 4,5 tha-1 na superfície (T2); (c) três aplicações de $1,5 \mathrm{t} \mathrm{ha}^{-1}$ anualmente na superfície (T3); e (d) 4,5 t $\mathrm{ha}^{-1}$ incorporadas a $0,2 \mathrm{~m}$ (T4). Nas subparcelas, foram 
aplicadas 3, 6 e $9 \mathrm{t} \mathrm{ha}^{-1}$ de gesso em superfície, e houve mais um tratamento que não recebeu gesso.

As aplicações de calcário dolomítico e de gesso agrícola foram realizadas em julho e em outubro de 1998 respectivamente. O calcário, quando incorporado, foi aplicado em duas etapas consecutivas. A primeira constou de aplicação manual de metade da dose, antes da aração com arado de discos, a $20 \mathrm{~cm}$ de profundidade. Na segunda etapa, foi aplicado o restante do calcário, manualmente, após a aração e imediatamente antes da gradagem com grade niveladora. No tratamento com parcelamento anual de calcário na superfície, a segunda aplicação foi em maio de 1999, e a terceira em maio de 2000.

Amostras de terra foram coletadas logo após a colheita da soja, em maio de 2003, retirando-se, com trado, 12 subamostras por subparcela para compor uma amostra composta das camadas de $0-5 ; 5-10 ; 10-20 \mathrm{~cm}$, e cinco subamostras para a camada de $20-40 \mathrm{~cm}$. Desde a instalação do experimento até a coleta do solo foram desenvolvidas as seguintes culturas: soja (1998/1999), cevada (inverno/1999), soja (1999/2000), trigo (inverno/ 2000), soja (2000/2001), milho (2001/2002) e soja (2002/2003). A adubação na semeadura da soja foi de $75 \mathrm{~kg} \mathrm{ha}^{-1}$ de $\mathrm{P}_{2} \mathrm{O}_{5}$ e de $\mathrm{K}_{2} \mathrm{O}$, no primeiro cultivo, e 60 $\mathrm{kg} \mathrm{ha}^{-1}$ de $\mathrm{P}_{2} \mathrm{O}_{5}$ e de $\mathrm{K}_{2} \mathrm{O}$, nos outros três cultivos. Em cada cultivo de soja também foram aplicados 15 $\mathrm{kg} \mathrm{ha}^{-1}$ de S. A cevada recebeu fertilizantes nas doses de $75 \mathrm{~kg} \mathrm{ha}^{-1}$ de $\mathrm{N}$ e $92 \mathrm{~kg} \mathrm{ha}^{-1}$ de $\mathrm{P}_{2} \mathrm{O}_{5}$. O trigo recebeu $130 \mathrm{~kg} \mathrm{ha}^{-1}$ de $\mathrm{N}, 66 \mathrm{~kg} \mathrm{ha}^{-1}$ de $\mathrm{P}_{2} \mathrm{O}_{5}$ e de $\mathrm{K}_{2} \mathrm{O}$. A adubação utilizada para o milho foi de $78 \mathrm{~kg} \mathrm{ha}^{-1}$ de N, $120 \mathrm{~kg} \mathrm{ha}^{-1} \mathrm{P}_{2} \mathrm{O}_{5}$ e $90 \mathrm{~kg} \mathrm{ha}^{-1} \mathrm{~K}_{2} \mathrm{O}$. Após a coleta, as amostras foram imediatamente secas ao ar, destorroadas e passadas em peneira de malha de $2 \mathrm{~mm}$ de diâmetro, acondicionadas em recipientes plásticos e armazenadas à sombra e temperatura ambiente até a realização das análises. Determinaram-se os teores de matéria orgânica (MO) e os valores de $\mathrm{pH}$ em CaCl $20,01 \mathrm{~mol} \mathrm{~L}^{-1}$, segundo os métodos descritos em RaIJ et al. (2001).

A partir das amostras coletadas e armazenadas, procederam-se as extrações para quantificação do $\mathrm{Al}$ trocável (Al- $\mathrm{KCl}$ ), e do $\mathrm{Al}$ trocável + não trocável $\left(\mathrm{Al}-\mathrm{CuCl}_{2}\right)$. Para tal, foram pesados 2 g de solo para cada extração e acondicionados em tubos distintos de centrífuga com $60 \mathrm{~mL}$ de capacidade. Na seqüência foram adicionados $20 \mathrm{~mL}$ $\mathrm{KCl} 1 \mathrm{~mol} \mathrm{~L}^{-1}$ ou $20 \mathrm{~mL}$ de $\mathrm{CuCl}_{2} 0,5 \mathrm{~mol} \mathrm{~L}^{-1}$, seguindose com agitação em mesa horizontal a $150 \mathrm{rpm}$ durante uma hora. Posteriormente, a suspensão foi centrifugada a $1500 \mathrm{rpm}$, durante 30 minutos. O Al obtido na extração com $\mathrm{KCl}$ foi titulado com $\mathrm{NaOH}$ $0,025 \mathrm{~mol} \mathrm{~L}^{-1}$, enquanto o $\mathrm{Al}$ extraído em $\mathrm{CuCl}_{2}$ foi determinado no ICP-OES. A diferença entre os teores de $\mathrm{Al}$ extraídos com cloreto de cobre e de potássio (Al$\mathrm{CuCl}_{2}-\mathrm{Al}-\mathrm{KCl}$ ) correspondeu ao $\mathrm{Al}$ não trocável (Figueiredo e Almeida, 1991).

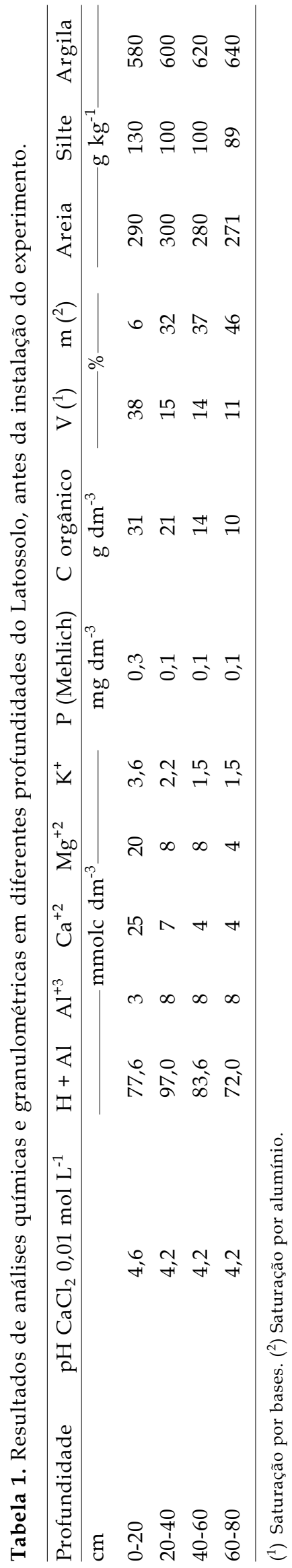

Bragantia, Campinas, v.66, n.3, p.487-495, 2007 
As variáveis foram submetidas à análise de variância seguindo o modelo em parcelas subdivididas. Como o efeito do gesso e da interação entre os tratamentos de calagem e gesso não foi significativo, as formas de aplicação de calcário foram comparadas pelo teste de Duncan a 5\%, e consideraram-se as doses de gesso nas subparcelas como repetições dos tratamentos de calcário, totalizando 12 repetições.

\section{RESULTADOS E DISCUSSÃO}

A aplicação de calcário aumentou o $\mathrm{pH}$ do solo até $40 \mathrm{~cm}$ de profundidade (Tabela 2). A calagem na superfície, com ou sem parcelamento da dose, proporcionou maior correção da acidez ativa na camada superficial do solo $(0-5 \mathrm{~cm})$ do que quando o calcário foi incorporado. No entanto, a incorporação do calcário foi mais eficiente do que a calagem superficial na correção da acidez ativa nas profundidades de $5-10 \mathrm{~cm}$ e de $10-20 \mathrm{~cm}$. Maiores detalhes da correção da acidez do solo para este mesmo local são encontrados em CAIRES et al. (2004).

Os teores de MO diminuíram ao longo do perfil do solo (Figura 1), mas não foram afetados pelos tratamentos em nenhuma das profundidades estudadas. Um dos efeitos da calagem e da incorporação de resíduos vegetais é a elevação da atividade biológica no solo, atribuída ao aumento do $\mathrm{pH}$ e à disponibilidade de nutrientes e de substratos orgânicos, com conseqüente aumento da taxa de decomposição da MO nativa ou adicionada (MENDONÇA e Rowell, 1994). Esses efeitos não foram constatados no presente estudo devido ao tempo transcorrido desde a instalação do experimento até a coleta das amostras, que totalizou 58 meses. Entretanto, em um tempo bem menor (14 meses), AlLEONI et al. (2003) constataram redução do estoque $\mathrm{MO}$ do solo em área de SPD no Estado do Paraná, com maiores diferenças entre o tratamento testemunha e aquele com incorporação do calcário.

Tabela 2. Valores de $\mathrm{pH}$ e teores de $\mathrm{Al}$ trocável $(\mathrm{Al}-\mathrm{KCl})$, $\mathrm{Al}$ trocável + não trocável $\left(\mathrm{Al}-\mathrm{CuCl}{ }_{2}\right)$ e $\mathrm{Al}$ não trocável, em várias profundidades de um Latossolo sob sistema plantio direto, em função das formas de aplicação do calcário

\begin{tabular}{|c|c|c|c|c|c|}
\hline Profundidade & Tratamento & $\mathrm{pH} \mathrm{CaCl}{ }_{2}$ & $\mathrm{Al}-\mathrm{KCl}$ & $\mathrm{Al}-\mathrm{CuCl}_{2}$ & Al não trocável \\
\hline $\mathrm{cm}$ & & & 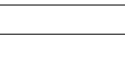 & $\mathrm{mmol}_{\mathrm{c}} \mathrm{kg}^{-1}$ & \\
\hline \multirow[t]{4}{*}{$0-5$} & $\mathrm{~T} 1$ & $4,6 \mathrm{c}$ & 1,4 & $38,7 \mathrm{a}$ & $37,3 \mathrm{a}$ \\
\hline & $\mathrm{T} 2$ & 5,9 a & $\mathrm{nd}^{*}$ & $19,2 \mathrm{~b}$ & $19,2 \mathrm{~b}$ \\
\hline & T3 & $5,9 \mathrm{a}$ & nd & $18,7 \mathrm{~b}$ & $18,7 \mathrm{~b}$ \\
\hline & $\mathrm{T} 4$ & $5,3 \mathrm{~b}$ & nd & $21,7 \mathrm{~b}$ & $21,7 \mathrm{~b}$ \\
\hline \multirow[t]{4}{*}{$5-10$} & $\mathrm{~T} 1$ & $4,3 \mathrm{c}$ & $4,7 \mathrm{a}$ & 41,6 a & 36,9 a \\
\hline & $\mathrm{T} 2$ & $4,7 \mathrm{~b}$ & $1,1 \mathrm{~b}$ & $35,4 \mathrm{ab}$ & $34,3 \mathrm{a}$ \\
\hline & T3 & $4,9 \mathrm{~b}$ & $1,0 \mathrm{~b}$ & $32,9 \mathrm{bc}$ & $31,9 \mathrm{ab}$ \\
\hline & $\mathrm{T} 4$ & $5,1 \mathrm{a}$ & $0,4 \mathrm{c}$ & $26,3 \mathrm{c}$ & $25,9 \mathrm{~b}$ \\
\hline \multirow[t]{4}{*}{$10-20$} & $\mathrm{~T} 1$ & $4,2 \mathrm{c}$ & $6,6 \mathrm{a}$ & $49,1 \mathrm{a}$ & 42,5 a \\
\hline & $\mathrm{T} 2$ & $4,3 \mathrm{~b}$ & $4,2 \mathrm{~b}$ & $42,1 \mathrm{~b}$ & $37,9 \mathrm{ab}$ \\
\hline & $\mathrm{T} 3$ & $4,3 \mathrm{~b}$ & $4,8 \mathrm{~b}$ & $37,3 \mathrm{~b}$ & $32,5 \mathrm{bc}$ \\
\hline & $\mathrm{T} 4$ & $4,8 \mathrm{a}$ & $1,1 \mathrm{c}$ & $30,1 \mathrm{c}$ & $29,0 \mathrm{c}$ \\
\hline \multirow[t]{4}{*}{$20-40$} & $\mathrm{~T} 1$ & $4,2 \mathrm{~b}$ & $6,0 \mathrm{a}$ & 43,6 a & 37,6 a \\
\hline & $\mathrm{T} 2$ & $4,4 \mathrm{a}$ & $3,8 \mathrm{~b}$ & $41,2 \mathrm{a}$ & 37,4 a \\
\hline & $\mathrm{T} 3$ & $4,4 \mathrm{a}$ & $3,6 \mathrm{~b}$ & $38,7 \mathrm{a}$ & $35,1 \mathrm{ab}$ \\
\hline & $\mathrm{T} 4$ & $4,4 \mathrm{a}$ & $2,9 \mathrm{~b}$ & $32,4 \mathrm{~b}$ & $29,5 \mathrm{~b}$ \\
\hline
\end{tabular}

Tratamentos de calcário - T1: Testemunha; T2: 4,5 t ha ${ }^{-1}$ parcelada em três aplicações anuais de 1,5 t ha ${ }^{-1}$ em superfície; T3: 4,5 $\mathrm{t}$ ha ${ }^{-1}$ em uma única aplicação em superfície; T4: 4,5 $\mathrm{t} \mathrm{ha}^{-1}$ em uma única aplicação com incorporação a 0,2 m de profundidade.

Médias seguidas pela mesma letra não diferem dentro de cada profundidade a $5 \%$ pelo teste de Duncan. ${ }^{*}$ não detectado. 


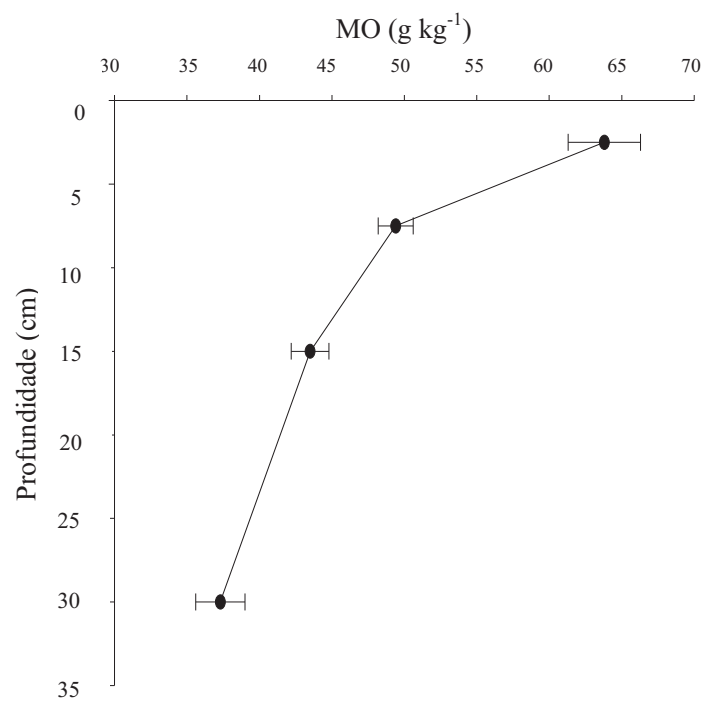

Figura 1. Distribuição dos teores de matéria orgânica (MO) do solo ao longo do perfil de um Latossolo sob SPD. As barras horizontais indicam o erro-padrão da média.

$\mathrm{O}$ teor de $\mathrm{Al}-\mathrm{KCl}$ foi reduzido pela calagem ao longo de todo o perfil de solo estudado (Tabela 2). Com o aumento do $\mathrm{pH}$ após a aplicação do corretivo, ocorre a precipitação $\mathrm{Al}^{+3}$ na forma de $\mathrm{Al}(\mathrm{OH})_{3}$ (KINRAIDE, 1991). $\mathrm{O}$ efeito do aumento do $\mathrm{pH}$ na redução dos teores de $\mathrm{Al}^{+3}$ foi confirmado pelas relações negativas entre ambos em todas as profundidades estudadas (Figura 2). Nos tratamentos com calcário, não foi encontrado $\mathrm{Al}^{+3}$ na camada de $0-5 \mathrm{~cm}$, devido ao $\mathrm{pH}$ mais elevado e possivelmente pelos altos teores de MO (Figura 1), que atuou na complexação do Al (MENDONÇA, 1995). A ação da $\mathrm{MO}$ em reduzir o $\mathrm{Al}^{+3}$ por complexação já foi demonstrado por ERnANi e Gianello (1983), em um experimento com aplicação de esterco bovino, cama de frango e cama de galinha, como alternativa de adubação de culturas em Litólico distrófico.

Diferenças entre as formas de calagem nos teores de $\mathrm{Al}^{+3}$ foram detectadas nas camadas de $5-10 \mathrm{~cm}$ e $10-20$ cm (Tabela 2), com maior redução do $\mathrm{Al}^{3+}$ após incorporação do calcário em relação à sua aplicação na superfície, tanto de forma parcelada como de uma única vez. Na profundidade de $20-40 \mathrm{~cm}$, a redução do $\mathrm{Al}^{+3}$ não dependeu da forma de aplicação do calcário, revelando que a incorporação mecânica do calcário não foi necessária para a redução do Al trocável nessa camada, após 58 meses da aplicação. Redução dessa forma de $\mathrm{Al}$ até $40 \mathrm{~cm}$ de profundidade também foi observada por OLIVEIRA e PAVAN (1996), aos 32 meses após a calagem superficial. KAMINSKI et al. (2005) avaliaram a aplicação superficial e incorporada de calcário (uma aração e duas gradagens), nas doses de 2,0; 8,5 e 17,0 tha ${ }^{-1}$ e verificaram que na dose mais alta houve equivalência entre as formas de aplicação até $7,5 \mathrm{~cm}$. Entretanto, em profundidades maiores (até 15 $\mathrm{cm}$ ), a saturação por $\mathrm{Al}$ somente manteve-se baixa quando o calcário foi incorporado.

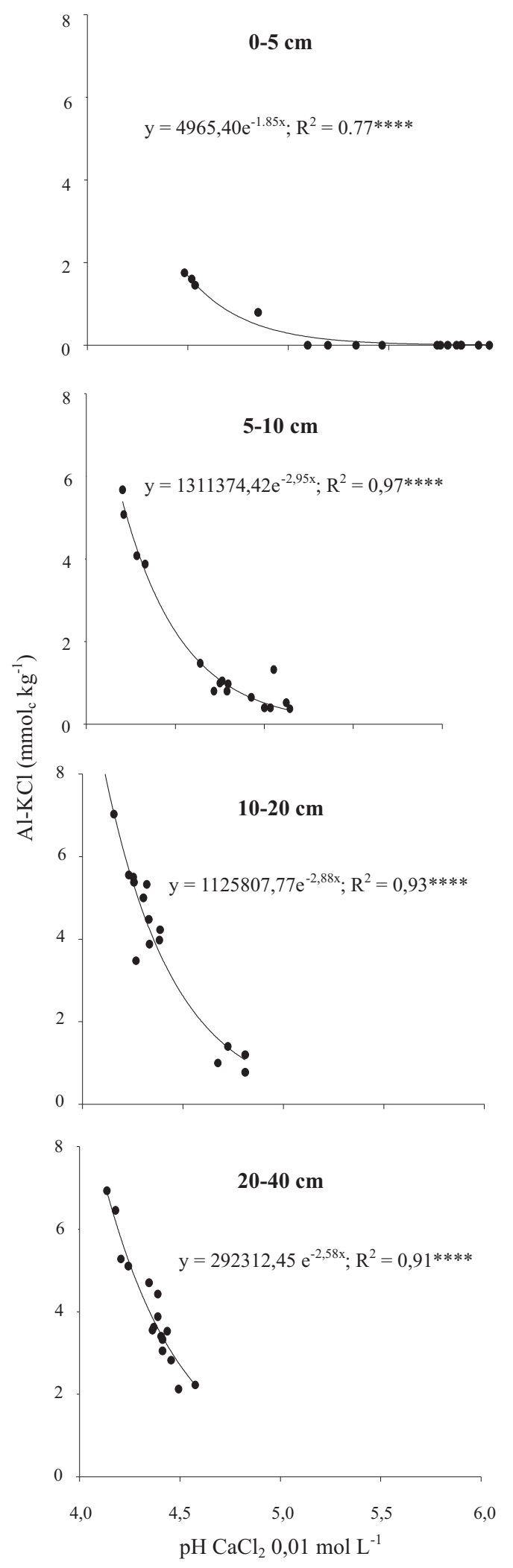

Figura 2. Relações entre o pH do solo e o Al trocável (Al-KCl) em amostras coletadas em diferentes profundidades de um Latossolo sob sistema plantio direto. ${ }^{* * *}$ Significativo a $0,01 \%$. 
A calagem superficial reduziu os teores de $\mathrm{Al}-\mathrm{CuCl}_{2}$ até $20 \mathrm{~cm}$ de profundidade, exceto na camada de 5-10 cm para o T2 - três aplicações de 1,5 $\mathrm{t} \mathrm{ha}^{-1}$ anualmente na superfície (Tabela 2). Nessa mesma camada, os tratamentos T2 e T3 - 4,5 tha ${ }^{-1}$ na superfície - não diferiram, e somente o primeiro diferiu do tratamento com calagem incorporada. Na profundidade de $0-5 \mathrm{~cm}$, não houve efeito das formas de aplicação do calcário, enquanto de $10-20 \mathrm{~cm}$ a calagem incorporada diferiu da superficial, conferindo maior redução aos teores de $\mathrm{Al}-\mathrm{CuCl}_{2}$. Na camada mais profunda $(20-40 \mathrm{~cm})$, somente a calagem com incorporação reduziu os teores de $\mathrm{Al}-\mathrm{CuCl}_{2}$. FIGUEIREDO e Almeida (1991), trabalhando com 26 amostras de solos ácidos do Estado de Santa Catarina, também observaram que os teores de $\mathrm{Al}$ extraídos com $\mathrm{CuCl}_{2}$ foram reduzidos com a aplicação de calcário. Entretanto, concluiu-se que o emprego da solução de $\mathrm{CuCl}_{2}$ não constitui método adequado para avaliar o Al precipitado pela calagem, porque o $\mathrm{pH}$ baixo dessa solução ( $\mathrm{pH} 3,3)$ diminui o $\mathrm{pH}$ da mistura solo/ solução, podendo redissolver o $\mathrm{Al}$ já precipitado.

Nesse mesmo trabalho, os autores constataram correlação negativa entre o $\mathrm{Al}-\mathrm{CuCl}_{2}$ e o pH do solo, o que coincide com os resultados verificados no presente estudo (Figura 3). Ressalta-se que o $\mathrm{Al}$ reativo estimado pela extração com $\mathrm{CuCl}_{2}$ decresce com o aumento do $\mathrm{pH}$ do solo.

Em todos os tratamentos e profundidades, a quantidade de $\mathrm{Al}-\mathrm{CuCl}_{2}$ foi maior do que aquela extraída com $\mathrm{KCl}$. Na média dos tratamentos, a extração feita com $\mathrm{Al}-\mathrm{CuCl}_{2}$ foi de 70, 36, 14 e 10 vezes maior do que a com $\mathrm{Al}-\mathrm{KCl}$, respectivamente, nas profundidades de $0-5,5-$ $10,10-20$ e $20-40 \mathrm{~cm}$. A diferença entre os teores de $\mathrm{Al}-\mathrm{CuCl}_{2}$ e Al-KCl diminuiu com o aumento da profundidade, o que pode ser atribuído à queda dos teores de $\mathrm{MO}$ (Figura 1) e ao aumento do $\mathrm{Al}-\mathrm{KCl}$, esse último favorecido pela redução dos valores médios de $\mathrm{pH}$ ao longo das profundidades (Tabela 2). Maiores valores de $\mathrm{Al}$ extraídos com $\mathrm{CuCl}_{2}$ do que com $\mathrm{KCl}$ também foram obtidos em vários solos ácidos americanos por Juo e KAMPRATH (1979). Segundo esses autores, o fato de o $\mathrm{CuCl}_{2}$ extrair mais $\mathrm{Al}$ do que o $\mathrm{KCl}$ suporta a previsão de que o $\mathrm{Al}$ extraído com $\mathrm{CuCl}_{2}$ é, provavelmente, um dos constituintes mais importantes para controlar o poder tampão de solos ácidos com $\mathrm{pH}$ de 4 a 6. Além disso, a extração com $\mathrm{CuCl}_{2}$ permite estimar o $\mathrm{Al}$ associado com a $\mathrm{MO}$ não extraído com $\mathrm{KCl}$, mas que reage com o calcário (HARGROve e THOMAS, 1984). KAMPRATH (1970) verificou que foi necessário o dobro da dose de calcário para neutralizar todo o $\mathrm{Al}$ trocável em solos ácidos, sugerindo a existência de outras formas de $\mathrm{Al}$ reativo não trocáveis com o $\mathrm{KCl}$, mas que reagem com o calcário e devem tornar-se importantes fontes fitotóxicas de Al.
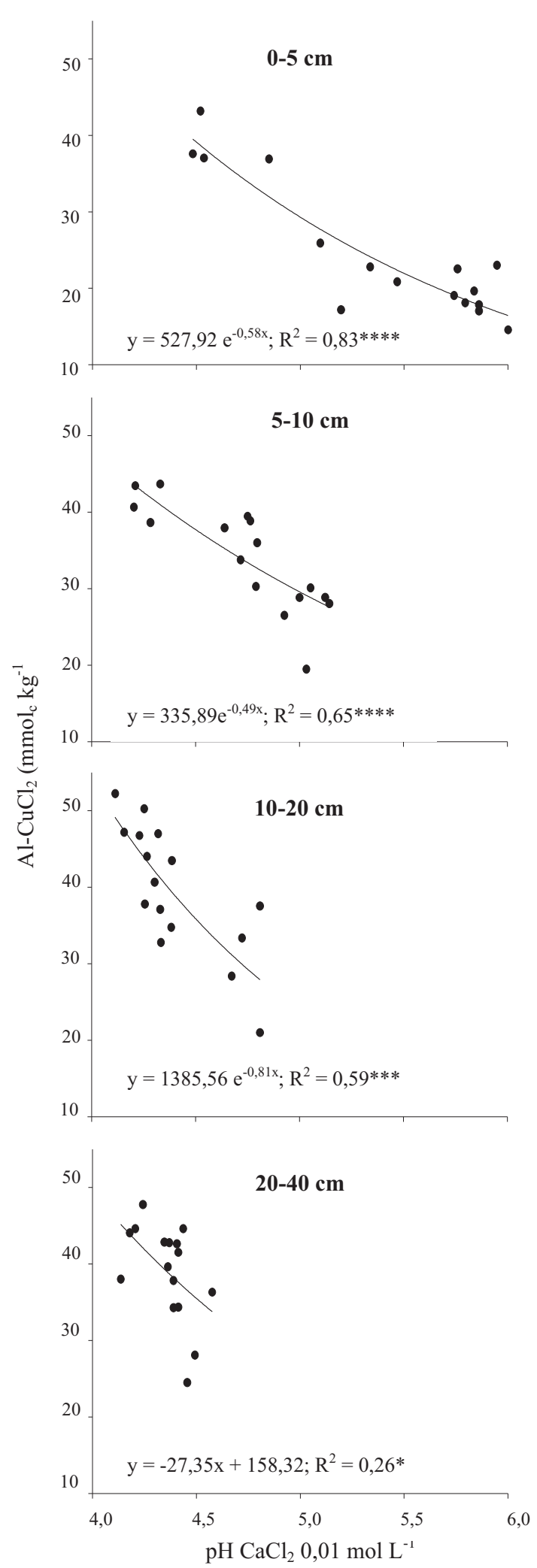

Figura 3. Relações entre o $\mathrm{pH}$ do solo e o $\mathrm{Al}$ trocável + não trocável $\left(\mathrm{Al}-\mathrm{CuCl}_{2}\right)$ em amostras coletadas em diferentes profundidades de um Latossolo sob sistema plantio direto. ${ }^{*} ; * *$ Significativo a $5 \%$ e a $0,1 \%$, respectivamente. 
O teor de Al não trocável variou com a aplicação de calcário (Tabela 2), sendo esse efeito independente da forma de aplicação apenas na primeira camada, onde todas elas reduziram esta forma de $\mathrm{Al}$. A redução do $\mathrm{Al}$ não trocável já era esperada, uma vez que se obtém a partir dos valores de $\mathrm{Al}-\mathrm{CuCl}_{2}$, os quais também reduziram com a aplicação de calcário. Nas demais camadas, houve diferença entre aplicação de calcário seguido de incorporação (T4) e aquele com três aplicações de $1,5 \mathrm{t} \mathrm{ha}^{-1}$ anualmente na superfície (T2). PAVAN (1983) incubou 14 solos ácidos com $\mathrm{CaCO}_{3}$ em quantidades teoricamente necessárias para reduzir a saturação por $\mathrm{Al} \mathrm{a} 60 \%, 45 \%, 30 \%, 15 \%$ e $0 \%$, além de duas vezes aquela necessária para reduzi-la a $0 \%$. Observou-se que a neutralização do $\mathrm{Al}$ pela calagem foi dependente do teor de MO dos solos, sendo o Al trocável neutralizado rapidamente, enquanto o $\mathrm{Al}$ não-trocável foi neutralizado lentamente.

A quantidade de $\mathrm{Al}$ complexado é dependente do pH (HARgrove e Thomas, 1984), e com a elevação do $\mathrm{pH}$ ocorre a formação de hidróxidos de alumínio (VANCE et al., 1996). O efeito negativo do aumento do $\mathrm{pH}$ do solo sobre os teores de $\mathrm{Al}$ não trocável, exceto para a última camada, foi confirmada pelos resultados apresentados na figura 4 . Apesar do $\mathrm{Al}$ trivalente ter vantagem sobre os cátions divalentes $\left(\mathrm{Ca}^{+2}, \mathrm{Mg}^{+2}\right.$, entre outros) para a formação de complexos com os ligantes orgânicos (VANCE et al., 1996), outra explicação atribuída para a redução do Al não trocável, é o aumento da concentração de Ca oriundo do calcário, que pode deslocar o $\mathrm{Al}$ dos complexos orgânicos (Mendonça e Rowell, 1994). Esses mesmos autores observaram redução do Al fraca e fortemente complexada pela $\mathrm{MO}$, na camada superficial do solo $(0-8 \mathrm{~cm})$, com a aplicação de calcário, o que foi explicada devido à remoção do $\mathrm{Al}$ pelo $\mathrm{Ca}$ oriundo do calcário; no entanto, esse $\mathrm{Al}$ foi precipitado, pois não se detectou aumento dos teores trocáveis.

A porcentagem de $\mathrm{Al}$ não trocável representou $98 \%, 95 \%, 91 \%$ e $89 \%$ do Al extraído nas profundidades de $0-5,5-10,10-20$ e 20-40 cm respectivamente. Sendo o Al não torcável a forma predominante desse cátion, práticas de manejo do solo que favoreçam a decomposição da MO, como o revolvimento do solo, parte do $\mathrm{Al}$ complexado pode ser disponibilizado às plantas, sobretudo em condições elevadas de acidez. Com a oxidação da $\mathrm{MO}$, ocorre passagem de formas de $\mathrm{Al}$ fortemente complexadas para formas mais reativas, o que pode acarretar aumento na liberação de $\mathrm{Al}$ para a solução do solo (MENDONÇA, 1995). Esse mesmo autor, ao promover a oxidação da MO com peróxido de hidrogênio em Latossolo Vermelho-Amarelo textura argilosa e em Latossolo Vermelho-Escuro textura média sob cerrado, observou, em ambos os solos, a liberação de Al para a solução do solo.

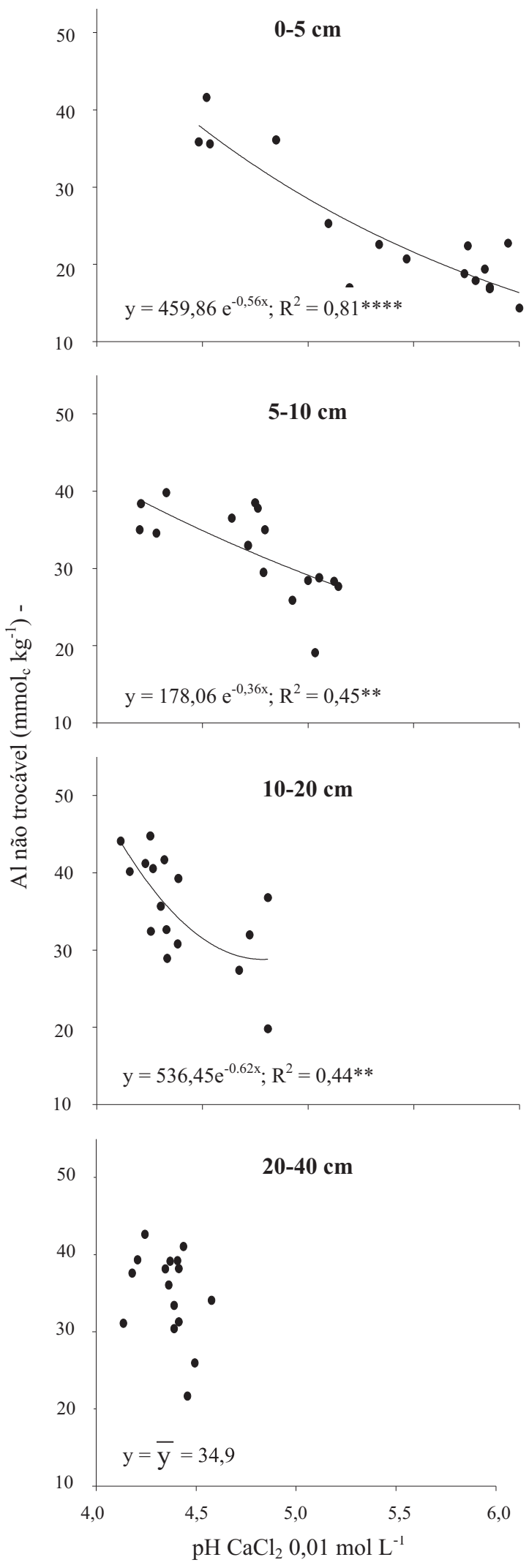

Figura 4. Relações entre o $\mathrm{pH}$ do solo e o $\mathrm{Al}$ não trocável do solo em amostras coletadas em diferentes profundidades de um Latossolo sob sistema plantio direto. ${ }^{* *} ;{ }^{* *}$ Significativo a $1 \%$ e a $0,1 \%$ respectivamente. ns: não significativo. 
Apesar da forte interação existente entre o Al e a MO, não foi verificada correlação significativa $(P>0,05)$ entre eles em nenhuma das camadas estudas, porque a calagem reduziu os teores de Al não trocável (Tabela 2) e não alterou os teores de MO do solo (Figura 1). Destaca-se que os resultados do presente estudo foram obtidos em diferentes condições de acidez, mas no mesmo tipo de solo e sistema de rotação de culturas, que tem influência direta no estoque de carbono orgânico do solo (BAyer et al., 2004). Provavelmente, a complexação está relacionada ainda com o grau de humificação da MO (Garcia-Rodeja et al., 2004). Figueiredo e Almeida (1991), em estudo com 26 amostras de solos ácidos do Estado de Santa Catarina, obtiveram correlação significativa e positiva entre os teores de $\mathrm{MO}$ e os valores de $\mathrm{Al}$ não trocável, o que, segundo os autores, sugere a influência da matéria orgânica na complexação do alumínio do solo. É importante ressaltar que no referido trabalho, foram estudados vários tipos de solo, com teores distintos de MO (25,0 a $280 \mathrm{~g} \mathrm{~kg}^{-1}$ de $\mathrm{MO})$ em condições semelhantes de acidez $\left(\mathrm{pH}_{\mathrm{H} 2 \mathrm{O}}\right.$ entre 3,9 e 5,0), ao contrário dos resultados apresentados neste estudo.

Não foi detectado efeito do gesso nos teores de $\mathrm{Al}-\mathrm{KCl}, \mathrm{Al}-\mathrm{CuCl}_{2}$ ou $\mathrm{Al}$ não trocável em nenhuma das profundidades estudadas. Entretanto, deve-se considerar que as determinações foram feitas 55 meses após a aplicação de gesso. Em um período de tempo bem menor após a gessagem (14 meses), CAIRES et al. (1999) verificaram que a aplicação superficial de gesso reduziu o $\mathrm{Al}$ trocável nas camadas de 5-10; $20-40 ; 40-60$ e $60-80 \mathrm{~cm}$ em Latossolo Vermelho distrófico sob SPD. Muitos mecanismos têm sido atribuídos como responsáveis pela redução desta forma de Al com a aplicação de gesso, como a formação do par iônico $\mathrm{AlSO}_{4}{ }^{+}$, aumento do $\mathrm{pH}$ da solução do solo e complexação do Al pelo fluoreto (SHAimberg et al., 1989).

\section{CONCLUSÕES}

1. Mesmo em condições de elevada acidez, os teores de Al trocável foram muitos baixos, sendo a forma não trocável a predominante em todas as profundidades avaliadas.

2. A calagem neutralizou o alumínio na forma trocável, e também parte daquele não-trocável. Ao mesmo tempo, essas formas de $\mathrm{Al}$ se relacionaram negativamente com o $\mathrm{pH}$ do solo.

3. O gesso não alterou os teores de Al trocável ou não trocável do solo aos 55 meses após sua aplicação até a profundidade de $40 \mathrm{~cm}$.

\section{AGRADECIMENTOS}

Ao CNPq, pela concessão de bolsa de mestrado ao primeiro autor, e de produtividade em pesquisa ao segundo e terceiro autores desse artigo.

\section{REFERÊNCIAS}

ALLEONI, L.R.F.; ZAMBROSI, F.C.B.; MOREIRA, S.G.; PROCHNOW, L.I.; PAULETTI, V. Liming and electrochemical attributes of an Oxisol under no tillage. Scientia Agricola, Piracicaba, v.60, p.119-123, 2003.

ALLEONI, L.R.F.; CAMBRI, M.A.; CAIRES, E.F. Atributos químicos de um Latossolo de cerrado sob plantio direto, de acordo com doses e formas de aplicação de calcário. Revista Brasileira de Ciência do Solo. Viçosa, v.29, p.923-934, 2005.

ALVAREZ, E.; MONTERROSO, C.; FERNÁNDEZ MARCOS, M.L. Aluminium fractionation in Galician (NW Spain) Forest soils as related to vegetation and parent material. Forest Ecology and Management, Wageningen, v.166, p.193-206, 2002.

BAYER, C.; MARTIN-NETO, L.; MIELNICZUK, J.; PAVINATO, A. Armazenamento de carbono em frações lábeis da matéria orgânica de um Latossolo Vermelho sob plantio direto. Pesquisa Agropecuária Brasileira, Brasília, v.7, p.677-683, 2004.

CAIRES, E.F.; CHUERI, W.A.; MADRUGA. E.F.; FIGUEIREDO, A. Alterações de características químicas do solo e resposta da soja ao calcário e gesso aplicados na superfície em sistema de cultivo sem preparo do solo. Revista Brasileira de Ciência do Solo, Viçosa, v.22, p.27-34, 1998.

CAIRES, E.F.; FONSECA, A.F.; MENDES, J.; CHUEIRI, W.A.; MADRUGA, E.F. Produção de milho, trigo e soja em função das alterações das características químicas do solo pela aplicação de calcário e gesso na superfície, em sistema de plantio direto. Revista Brasileira de Ciência do Solo, Viçosa, v.23, p.315-327, 1999.

CAIRES, E.F.; KUSMAN, M.T.; BARTH, G.; GARBUIO, F.J. PADILHA, J.M. Alterações químicas do solo e resposta do milho à calagem e aplicação de gesso. Revista Brasileira de Ciência do Solo, Viçosa, v.28, p.125-136, 2004.

CAIRES, E.F.; ALLEONI, L.R.F.; CAMBRI, M.A.; BARTH, G. Surface Application of Lime for Crop Grain Production Under a No-Till System. Agronomy Journal, Madison, v.97, p.791798, 2005.

CAIRES, E.F.; GARBUIO, F.J.; ALLEONI, L.R.F; CAMBRI, M.A. Calagem superficial e cobertura de aveia preta antecedendo os cultivos de milho e soja em sistema plantio direto. Revista Brasileira de Ciência do Solo, Viçosa, v.30, p.87-98, 2006.

CAMBRI, M.A. Calagem e formas de alumínio em três localidades sob sistema de plantio direto. 2004. 83 f. Tese (Doutorado em Agronomia) - Escola Superior de Agricultura "Luiz de Queiroz", Universidade de São Paulo, Piracicaba. 
CANCÈS, B.; PONTHIEU, M.; CASTREC-ROUELLE, M.; AUBRY, E.; BENEDETTI, M.F. Metal ions speciations in a soil and its solution: experimental data and model results. Geoderma, Amsterdam, v.113, p.641-355, 2003.

EMPRESA BRASILEIRA DE PESQUISA AGROPECUÁRIA. Centro Nacional de Pesquisa de Solos. Manual de análises químicas de solos, plantas e fertilizantes. 2.ed. Rio de Janeiro, 1997. 212p.

ERNANI, P.R.; GIANELLO, C. Diminuição do alumínio trocável do solo pela incorporação de esterco de bovinos e cama de aviário. Revista Brasileira de Ciência do Solo, Campinas, v.7, p.191-165, 1983.

FIGUEIREDO. O.A.R.; ALMEIDA, J.A. Quantificação das formas trocáveis e não trocáveis de alumínio em solos ácidos do estado de Santa Catarina. Revista Brasileira de Ciência do Solo, Campinas, v.15, p.151-156, 1991.

GARCÍA-RODEJA, E.; NÓVOA, J.C.; PONTEVEDRA, X.; MARTÍNEZ-CORTÍZES, A.; BUURMAN, P. Aluminium fractionation of European volcanic soils by selective dissolution techniques. Catena, Amsterdam, v.56, p.155-183, 2004.

HARGROVE, W.L.; THOMAS, G.W. Extraction of aluminum from aluminum-organic matter complexes. Soil Science Society of America Journal, Madison, v. 45, p.151-153, 1981.

HARGROVE, W.L.; THOMAS, G.W. Extraction of aluminum from aluminum-organic matter in relation to titratable acidity. Soil Science Society of America Journal, Madison, v.48, p.14581460, 1984.

JARDINE, P.M.; ZELAZNY, L.W.. Environmental chemistry of aluminum-organic complexes. In: SPOSITO, G. (Ed) The enviromental chemistry of aluminum. 2.ed. Flórida: Lewis Publishers, 1996. p.169-220.

JUO. A.S.R.; KAMPRATH, E.J. Copper chloride as na extractant for estimating the potencially reactive aluminum pool in acid soils. Soil Science Society of America Journal, Madison, v.43, p.35-38, 1979.

KAISER, K., ZECH, W. Defects in estimation of aluminum in humus complexes of podzolic soils by pyrophosphate extraction. Soil Science, Madison, v.161, p.452-458, 1996.

KAMINSKI, J.; RHEINHEIMER, S.D.; GATIBONI, C.L.; BRUNETTO, G.; SILVA, L.S. Eficiência da calagem superficial e incorporada precedendo o sistema plantio direto em um Argissolo sob pastagem natural. Revista Brasileira de Ciência do Solo, Viçosa, v.29, p.573-580, 2005.

KAMPRATH, E.J. Exchangeable Al as a criteria for liming leached mineral soils. Soil Science Society of America Proceeding, Madison, v.34, p.252-254, 1970.

KINRAID, T.B. Identity of the rhizotoxic aluminum species. Plant Soil, The Hague, v.134, p.167-178, 1991.

LOVATO, T.; MIELNICZUK, J.; BAYER, C.; VEZZANI, F. Adição de carbono e nitrogênio e sua relação com estoques no solo e com o rendimento do milho em sistemas de manejo. Revista Brasileira de Ciência do Solo, Viçosa, v.28, p.175-187, 2004.
MENDONÇA, E.S. Oxidação da matéria orgânica e sua relação com diferentes formas de alumínio de Latossolos. Revista Brasileira de Ciência do Solo, Campinas, v.19, p.25-30, 1995.

MENDONÇA, E.S.; ROWELL, D.L. Dinâmica do alumínio e de diferentes frações orgânicas de um latossolo argiloso sob cerrado e soja. Revista Brasileira de Ciência do Solo, Campinas, v.18, p.295-303, 1994.

OATES, K.M.; KAMPRATH, E.J. Soil acidity and limming: II. Evaluation of using aluminium extracted by various chloride salts for determining lime requeriments. Soil Science Society of America Journal, Madison, v.47, p.690-692, 1983.

OLIVEIRA, E.L., de; PAVAN, M.A. Control of acidity in no tillage system soybean production. Soil \& Tillage Research, Amsterdam, v.38, p.47-57, 1996.

PAVAN, M.A. Alumínio em solos ácidos do Paraná: relação entre o alumínio não trocável, trocável e solúvel, com o pH, CTC, porcentagem de saturação de $\mathrm{Al}$ e matéria orgânica. Revista Brasileira de Ciência do Solo, Campinas, v.7, p.39-46, 1983.

PAVAN, M.A.; BLOCH, M.F.; ZEMPULSKI, H.C.; MIYAZAWA, M.; ZOCOLER, D.C. Manual de análise química do solo e controle de qualidade. Londrina: Instituto Agronômico do Paraná, 1992. 38p. (Circular 76)

PIONKE, H.B.; COREY, R.B. Relations between acidic aluminum and soil $\mathrm{pH}$, clay, and organic matter. Soil Science Society of America Proceeding, Madison, v.34, p.749-752, 1967.

RAIJ, B. van; ANDRADE, J.C.; CANTARELLA, H.; QUAGGIO, J.A. Análise química para avaliação da fertilidade de solos tropicais. Campinas: Instituto Agronômico, 2001. 284p.

SHAIMBERG, I.; SUMNER, M.E.; MILLER, W.P.; FARINA, M.P.W.; PAVAN, M.A. Use of gypsum on soils: a review. Advances in Soil Science, New York, v.9, p.1-101, 1989

SHIGEMITSU, A. Extraction of active aluminum from acid soils in Japan with different reagents. Geoderma, Amsterdam, v.14, p.63-74, 1975.

URRUTIA, M.; MACÍAS, F.; GARCÍA-RODEJA, E. Evaluación del $\mathrm{CuCl}_{2}$ y del $\mathrm{LaCl}_{3}$ como extractantes de aluminio en suelos ácidos de Galicia. Nova Acta Científica Compostelana (Bioloxía), Santiago de Compostela, v.5, p.173-182, 1995.

VANCE, G.F.; STEVENSON, F.J.; SIKORA, F.J. Environmental chemistry of aluminum-organic complexes. In: SPOSITO, G. (Ed.). The enviromental chemistry of aluminum. 2.ed. Flórida: Lewis Publishers, 1996. p.169-220.

ZAMBROSI, F.C.B.; ALLEONI, L.R.F.; CAIRES, E.F. Aplicação de gesso agrícola e especiação iônica da solução de Latossolo sob sistema plantio direto. Ciência Rural, Santa Maria, v.37, p.110-117, 2007. 